\title{
Evaluation Method for Performance of Formwork Process of Construction Industry
}

\author{
Wen-Pei Sung*1, Kuen-Suan Chen ${ }^{2}$, Wernshyuan Song ${ }^{3}$ and Yu-Yin Tsai ${ }^{4}$ \\ ${ }^{1}$ Associate Professor, Department of Landscape Design and Management, National Chin-Yi Institute of Technology, R.O.C. \\ ${ }^{2}$ Professor, Department of Industrial Engineering and Management, National Chin-Yi Institute of Technology, R.O.C. \\ ${ }^{3}$ Instructor, Department of Accounting, National Taichung Institute of Technology, R.O.C. \\ ${ }^{4}$ Instructor, Department of Business Administration, Hsiuping Institute of Technology, R.O.C.
}

\begin{abstract}
Resource and material costs are significant proportion of total construction cost in civil and construction engineering. The purchase of these resources and materials need to coordinate with different suppliers. The selection of suppliers plays an important role in construction process management. This research will focus on delivery and try to define an index of performance of formwork process to evaluate the suppliers. Moreover, the index also provides a convenient and effective way to evaluate various suppliers' performance of formwork process at the same time. This paper uses Boyle's rate of tallied tolerance of index of process capability and Taguchi Loss Function as a non-dimensional equation to define an index of performance of formwork process that has the rate of as scheduled delivery as basis. In addition, this paper also refers to Vännman's method to develop an analysis chart of performance of multi-formwork process to compare the performance of every supplier. When implementing the analysis method developed by this paper into practical examples, it is very convenient and accurate to express the relationship between the index of performance of formwork process and rate of as scheduled delivery.
\end{abstract}

Keywords: index of delivery performance; analysis chart of delivery performance; evaluation procedure of delivery performance

\section{Introduction}

$20 \%$ to $30 \%$ of total construction costs are formwork process costs of reinforced concrete construction. The formwork process cost could go up to $40 \%$ to $60 \%$ of the total construction cost in complex construction. Formwork plan should first be drawn and formwork should be made according to the plan. It is necessary to first consider if the formwork process system is applicable and economical to a particular construction; included fabrication, installation and removal process (Gudmestad and Warland 1992). The quality of formwork process and the purchase of formworks will affect the construction cost, construction safety and construction process control. The purchase of formworks is especially important since it is necessary to buy applicable and quality formworks at low prices. In addition, it is also vital for the materials to be delivered to the construction site on time in order to avoid inventory cost and low quality construction as a result

*Contact Author: Wen-Pei Sung, Associate Professor,

National Chin-Yi Institute of Technology

No. 35, Ln. 215, Chung Suan Rd. Sect. I, Taiping,

Taichung, Taiwan 41111, R.O.C.

Tel: +886-4-2393-0731 Fax: +886-4-2393-0737

e-mail: sung809@chinyi.ncit.edu.tw

(Received January 14, 2003; accepted September 29, 2003) to rush the project. To comply the three components of construction process management-construction time, quality and cost control, a process management curve is often used to describe the relationship between completed construction and construction time. Thus, to achieve the goal of construction process control and high construction quality, selecting a formwork supplier with care is an important factor in construction process management. Therefore, Hanna et al. proposed the development and knowledge acquisition of an expert system developed to assist the formwork selection in making that decision (Hanna et al. 1992) and Dou et al. proposed product data management to guarantee the quality and effect of integrating the information, functions and processes, provided an instructional formwork for decision-making (Dou et al. 2001).

Taiwan often uses wooden formwork system in reinforced concrete construction. When seven days after the pouring of reinforced concrete, the wooden formwork can be torn apart. The wooden formwork can be used for approximately three to five times, the number of usage and quality are mainly affected by three factors, working attitudes, efficiency and stripping process (Ling and Leo 2000). Besides safety, formwork is also important for the quality of the façade of the building, construction time and cost. Low quality of formworks often cause accidents in the public or after tearing out 
the formworks, cost is often increased due to unleveled works. The construction companies in Taiwan regularly work with different formwork suppliers due to limited capital. Companies not only ask the suppliers for low cost formworks, but the performance that will affect the construction process and quality are also equally important. For instance, in wooden formwork system, the construction company often requires the suppliers to provide high quality materials and proficient personnel. Construction companies require the inspection and maintenance of sheathing, joist, stud and shores. And they should be completed no more than seven days. If the inspection, maintenance, and assembling of formworks take less than three days, the inspection and maintenance might not be reliable and thus, will affect the quality of formwork construction. Moreover, if the formworks are delivered to the construction sites too early, taking up spaces in warehouse might cause problems for the construction process. On the other hand, if the delivery to the construction site is delayed, any rush work will result in low quality and increase in cost. Actually, project viability and contractor profitability are both determined by construction speed (Render 1995). Therefore, this paper will provide a way for formwork suppliers to evaluate their performance and construction companies to objectively select a formwork supplier.

This paper utilizes Dickson's (Dickson 1966) research as a basis in inventing a way for evaluating performance. Dickson's research pointed out that quality and delivery are the two most important features demanded by customers. Twenty-five years later, Weber and others used Dickson's research results for reference and concluded once again the extreme importance of quality and considerable importance of deliver. High quality and reasonable delivery are highly valued by customers; thus, they are key factors for formwork suppliers to get orders. Weber (Weber 1991) and others also specifically investigated on suppliers who used JIT (Just-in-Time) system and concluded the significance of quality and delivery just like what they have found out before. There were many studies that focus on the evaluation methods of quality performance. The index of performance of production process is one of the effective tools in evaluating the performance of production process and quality of the product. Statistics experts and quality engineers such as Kane (Kane 1986), Chan et al. (Chan 1988), Boyles (Boyles 1991), Pearn et al. (Pearn 1992), Boyles (Boyles 1994), Chen (Chen 1998), Chen et al. (Chen 2001) and Chen et al. (Chen 2002) concentrated their studies in this field. The purpose of these studies is to provide clients a more convenient, effective and reliable evaluation method of production process. It is essential to provide a way to effectively evaluate the performance of formwork process after methods in evaluating quality has already been searched.

\section{Establishing Analysis Model}

The reason of collapse or burst of form is because of too large momentum and pressure under pouring of concrete, unqualified material of support or insufficient confined force of column, unsatisfactory design and combination of from system. This disaster induces loss of life and property; besides, it affects the achieved percentage of scheduled engineering progress tremendously. Therefore, formwork process should include planning, designing, preparation and etc. This process can provide a perfect quality for construction rate of progress. Besides described as above, proficient construction personnel are another key factor. Because of restriction of material, engineering environment and usual practice of worker, and the wooden shoring systems are usually used in construction sites in Taiwan. On the other hand, for system of subcontract, the workers and materials of form take full responsibility of entrepreneur. The scales of form contractors are not too large that the manpower and financial capability are limited. Therefore, if the workload is overloading, form contractor has unsatisfactory maintenance, insufficient material of form and inadequate worker, and it will procrastinate time limit for a project. In order to attain the required time limit for a project, formworks are dashed off that increases capitalized costs and results in unqualified engineering quality.

If the number of projects are reduced, even though the supplier can have more personnel for maintenance, but other projects might be affected when starting some of them early. If the supplier works on the project according their schedule, human resources and materials will be idled and results an increase in fixed cost. Therefore, maintaining a reasonable workload is the best way to sustain construction quality and profits. According to above, suppliers should utilize system similar to Build To Order; BTO, since there's a significant relationship between the quality for formwork process and reduce construction time. Formwork process is the time from formwork maintenance or making to the completion of formwork assembling. The work time unit is in days. Because there are many changing factors (such as materials, construction personnel, or other nonconstruction factors) for the whole maintenance and assembling, the formwork process time will be varied. Thus, formwork process time is a random value. Assuming $X$ represents the actual formwork process time and a random value. Under limited personnel and resources, the construction quality and time will be affected when trying to shorten the process time. If the supplier tries to maintain quality by increasing the formwork process time, the supplier might be penalized for not meeting the deadline. Suppliers should focus on the characteristics of the whole project to establish a reasonable expected formwork process time $T$ in order to maintain quality and meeting deadline. $T$ should be smaller than the upper tolerable limit of formwork process time $U$ days so the formwork process can be 
completed on time. This paper calls $d=U-T$ to be the tolerable time for suppliers. The lower tolerable limit is $L=T-d$ to avoid any rush works that would affect the quality of formworks. The actual formwork process time $X$ has to be larger than $L$ to ensure the quality of formwork process. From the theory above, formwork process time is a nominal-the-best type. Figure 1 shows the tolerable delivery range formed by $(L, U)$ and the actual delivery $X$ is under the assumption of normal distribution $\left(X \sim N\left(\mu_{X}, \sigma_{X}\right)\right)$.

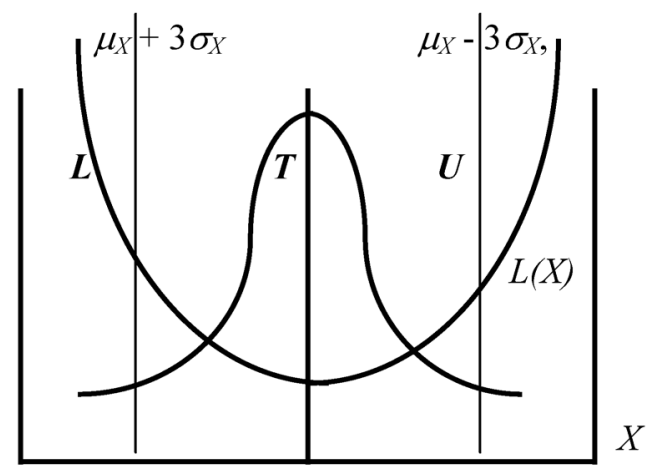

Fig. 1. Actual Formwork Process Time and Loss Function

Base on Taguchi's Loss Function shown in Figure 1, it is obvious that $L(X)=(X-T)^{2}$. It reveals when the actual process time excurse the expected process time that the value of loss function will be increased. When the average value $\mu_{X}$ of formwork process time equals the expected delivery $T$, the expected loss is at the lowest, and $L(X)$ is close 0 . When $X>U$, it represents that the formwork process time has been delayed and it indicates that the supplier has poor performance. The quality of construction will be affected and cause in increase in construction cost. Even though the formwork process time will not be affected when $X<L$, but it might affect the quality of other projects. An increase in fixed cost might happen due to any excessive personnel and materials. The two conditions described as above will cause an increase in expected loss when $L(X)^{\vee} \square 0$. In next section, an index of performance of suppliers' formwork will be established.

\section{Index of Performance of Formwork Process}

The performance of formwork process is concluded to be nominal-the-best type from the analysis above. The tolerable rage of formwork process varies for every construction due to different numbers of formwork and samples. This research modified Taguchi Loss Function to be a non-dimensional equation, which results the tolerable range of time of formwork process to be ( $L$, $U)$. Formwork process time is reasonable when the expected delivery $T$ falls into the range between $(L, U)$. The higher the possibility of formwork process meet the requirement, the better the performance of the suppliers. To accurately evaluate the performance of suppliers' formwork process, this research uses Boyles' (Boyles 1994) rate of tallied tolerance of index of process capability and the modified non-dimensional equation to establish an index of performance of formwork process shown as follows:

$$
D_{p}=\Phi^{-1}\left\{\frac{1}{2}\left(\Phi\left(\frac{U-\mu}{\sigma}\right)+\Phi\left(\frac{\mu-L}{\sigma}\right)\right)\right\}
$$

Where:

$\mu$ is the average of formwork process time; $\sigma$ is the standard deviation of formwork process time;

$\Phi$ represents the cumulative function of standard normal distribution.

The formwork process time is reasonable when $T$ falls between the ranges of $(L, U)$. Thus, $p$, the rate of meeting the expected formwork process can be expressed as follows:

$$
\begin{aligned}
p & =1-\mathrm{P}(L<X<U) \\
& =1-\mathrm{P}\left(\frac{L-\mu}{\sigma}<\frac{X-\mu}{\sigma}<\frac{U-\mu}{\sigma}\right) \\
& =1-\Phi\left(\frac{U-\mu}{\sigma}\right)+\Phi\left(\frac{L-\mu}{\sigma}\right) \\
& =1-\Phi\left(\frac{U-\mu}{\sigma}\right)-\Phi\left(\frac{\mu-L}{\sigma}\right) \\
& =2-2 \Phi\left(D_{p}\right)
\end{aligned}
$$

since

$$
D_{p}=\Phi^{-1}\left\{\frac{1}{2}\left(\Phi\left(\frac{U-\mu}{\sigma}\right)+\Phi\left(\frac{\mu-L}{\sigma}\right)\right)\right\}
$$

Therefore,

$$
\Phi\left(\frac{U-\mu}{\sigma}\right)+\Phi\left(\frac{\mu-L}{\sigma}\right)=2 \Phi\left(D_{p}\right)
$$

It is obvious that the index of performance of formwork process $D_{p}$ and the rate of meeting the expected formwork process $p$ have one to one mathematical relationship shown in Table 1. 
Table 1. Dp and Corresponding to $p$

\begin{tabular}{|c|c|c|c|c|c|}
\hline$D_{p}$ & $p$ & $D_{p}$ & $p$ & $D_{p}$ & $p$ \\
\hline 1.0 & 0.682689492 & 2.0 & 0.954499736 & 3.0 & 0.997300204 \\
\hline 1.1 & 0.728667878 & 2.1 & 0.964271159 & 3.1 & 0.998064794 \\
\hline 1.2 & 0.769860660 & 2.2 & 0.972193105 & 3.2 & 0.998625724 \\
\hline 1.3 & 0.806399031 & 2.3 & 0.978551780 & 3.3 & 0.999033152 \\
\hline 1.4 & 0.838486682 & 2.4 & 0.983604928 & 3.4 & 0.999326141 \\
\hline 1.5 & 0.866385597 & 2.5 & 0.987580669 & 3.5 & 0.999534742 \\
\hline 1.6 & 0.890401417 & 2.6 & 0.990677624 & 3.6 & 0.999681783 \\
\hline 1.7 & 0.910869074 & 2.7 & 0.993066052 & 3.7 & 0.999784401 \\
\hline 1.8 & 0.928139362 & 2.8 & 0.994889739 & 3.8 & 0.999855304 \\
\hline 1.9 & 0.942566880 & 2.9 & 0.996268373 & 3.9 & 0.999903807 \\
\hline
\end{tabular}

Table 1 demonstrates the larger the index of performance of formwork process, the higher the rate of meeting the expected formwork process. Therefore, index $D$ fully reflects the supplier's performance of formwork process.

\section{Analysis Chart of Performance of Formwork Process}

This paper consults the method of Vännman (Vännman 1999) when propose an analysis chart of performance of multi-formworks to accurately evaluate and compare the performance of different suppliers. The relationship between index value of performance of formwork process in Table 1 and the rate of meeting the expected formwork process should first be considered to establish a required index value of performance of formwork process. Table 2 illustrates different index values of performance of formwork process and their respected conditions of performance and suggestions. $v_{1}$ and $v_{2}$ can be regarded as industry background, competitions, suppliers' own expectations and etc.

Table 2. Performance Requirements and Suggestions of Formwork Process

\begin{tabular}{cccc}
\hline $\begin{array}{c}\text { Performance } \\
\text { Block }\end{array}$ & $\begin{array}{c}\text { Condition } \\
\text { of } \\
\text { Performan } \\
\text { ce }\end{array}$ & $\begin{array}{c}\text { Index Value of } \\
\text { Performance of } \\
\text { Formwork Process }\end{array}$ & Suggestions \\
\hline I & Poor & $D_{p}<v_{1}$ & Improve \\
II & Fair & $v_{1} \leq D_{p} \leq v_{2}$ & Maintain \\
III & Good & $D_{p}>v_{2}$ & Maintain/ \\
& & & Review \\
\hline
\end{tabular}

Two contour lines of $D_{p}=v_{1}$ and $D_{p}=v_{2}$ are drawn according to Table 2 shown in Figure 2 .

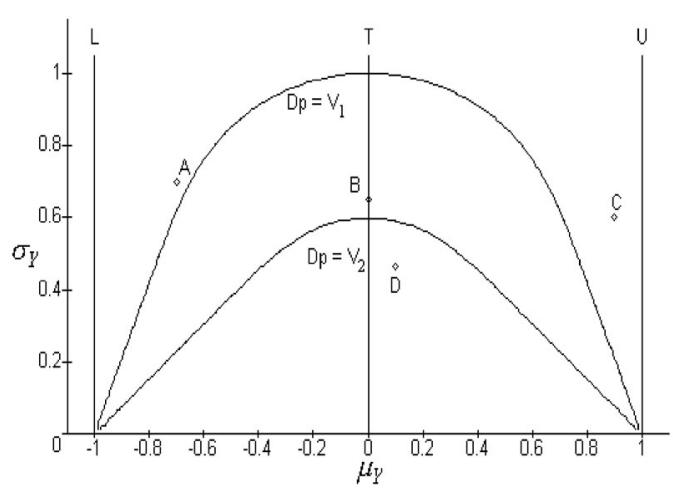

Fig. 2. The Analysis Chart of Performance of Multi-formworks

In Figure 2, $\mu$ is the transversal axis and $s$ is the ordinate. The contour lines formulated three performances of formwork process blocks that is called "The analysis chart of performance of Formworks." Hence, the performance coordinate of $(\mu, \sigma)$ created by the actual average performance of formwork process and standard deviation of different suppliers can be drawn on the same analysis chart. Moreover, the condition of supplier's performance can be easily observed from the blocks in Table 2. At the same time, suggestions can be provided.

There are four suppliers in Figure 2. Supplier A and C fall into performance I. Supplier B falls into performance Bock II, and Supplier D falls in performance Block III. Figure 2 illustrates that supplier A has delivered the formworks to the construction site too early which might cause inventory cost and affect construction process due to insufficient projects. Supplier C causes delays in construction process, which might cause an increase in costs. The reasons for the delay might be the supplier has too many projects going at the same time. One way to improve the problem is to hire more construction personnel, purchase more materials or reduce the number of projects. Even though Supplier D's performance is good, but there might be any expected problems that should be improved now to reduce cost. Supplier B's performance is fair. Thus, this performance should be maintained. Table 3 demonstrates the performance of these four suppliers.

Table 3. Index Value of Performance of Formworks and the Relevant Performance Condition

\begin{tabular}{cccc}
\hline \multirow{2}{*}{ Supplier } & $\begin{array}{c}\text { Performance } \\
\text { Block }\end{array}$ & $\begin{array}{c}\text { Performance } \\
\text { Condition }\end{array}$ & Suggestion \\
\hline A & I & Poor & Improve \\
B & II & Fair & Maintain \\
C & I & Poor & Improve \\
D & III & Good & Maintain/ \\
& & & Review \\
\hline
\end{tabular}




\section{Steps for Evaluating the Performance of Formwork Process}

Steps for evaluating capability and performance of formworks process are established from Section 3 and Section 4 of this paper so the suppliers and customers can conveniently assess the capability and performance of formwork process. Steps are as follows:

Step 1:Establish the values of $v_{1}$ and $v_{2}$ and drawn two contour lines of $D_{p}=v_{1}$ and $D_{p}=v_{2}$ in analysis chart of index of performance of formwork.

Step 2:Label performance Block I, II and III from top to bottom on the three blocks formed by the two contour lines (See Figure 2).

Step3:Gather actual formwork process data of all suppliers and calculate each supplier's $\mu$ value and $\sigma$ value.

Step 4:Suppliers' performance of formwork process can be shown when the computed values of $(\mu, \sigma)$ from Step 3 are plotted on the analysis chart of index of performance of formwork process.

Step 5:Create Table 3 based on the information from the analysis chart of index of performance of formwork process. This will provide decision makers a basis in choosing suppliers. At the same time, Table 3 also functions as a reference to suppliers in improving their performance.

\section{Practical Cases}

The index of performance of formwork process can be utilized in evaluating suppliers' capability and performance when selecting suppliers. A practical case is used to demonstrate the steps of how to evaluate suppliers' capability and performance of formwork process by applying the index of performance of formwork process. To save the budget of fixed up a building, the owner and architect designate the high standard form. The entrepreneur should reach the contract requirement of engineering quality and avoid engineering loss induced by unqualified form. Therefore, public engineering unit asks for supplier of form contractor the following: the contents of contract include timely supply of high standard form, clean away miscellaneous articles and maintain used form, and the fine form should be transported to site for combination of form in five days after tearing down form based on engineering demand. To save the cost of watching and heaping of form and avoid unexpected damage of other engineering work, form cannot be delivered to site too early. The time limit for a project will be put off because the forms transport to site too late. It induces to catch up the engineering schedule in which will affect the cost and engineering quality. Thus, contact subscribe that the best delivery date is five days (expected date 7 ), the early delivery date is three days (the lower tolerable limit date $L$ ), and the latest delivery date is seven days (the upper tolerable limit date $U$ ). The tolerable time $d$ for suppliers is two days. In this case, the performance of delivery of form supplier is required $D_{p}=v_{1}=2.6$ and $D_{p}=v_{2}=3.2$.
The rate of meeting the expected formwork process should be more than $99.07 \%$. There is three form suppliers: $F, O$ and $R$ submitted a tender. In order to choose the best form supplier, the formwork process records of these three formwork suppliers are used for evaluation. The form process records are listed on Table 4.

Table 4. F, AO and R's Record of Delivery

\begin{tabular}{ccccc}
\hline \multicolumn{5}{l}{$F$ formwork } \\
\hline 4 & 3 & 2 & 3 & 4 \\
4 & 2 & 3 & 3 & 3 \\
2 & 3 & 4 & 4 & 2 \\
\hline$O$ formwork & supplier's & delivery \\
\hline 5 & 5 & 4 & 4 & 5 \\
5 & 4 & 5 & 5 & 5 \\
6 & 5 & 5 & 5 & 5 \\
\hline$R$ formwork & supplier's & delivery \\
\hline 6 & 6 & 6 & 6 & 6 \\
7 & 5 & 6 & 5 & 6 \\
7 & 6 & 7 & 6 & 7 \\
\hline
\end{tabular}

Three formwork suppliers' $\mu_{Y}$ value, $\sigma_{Y}$ value and $D_{p}$ value calculated with the data from Table 4 are as follows:

$F$ supplier: $\mu_{Y}=-0.7667 \quad \sigma_{Y}=0.6188 D_{p}=2.50$

$O$ supplier: $\mu_{Y}=-0.0667 \sigma_{Y}=0.5164 D_{p}^{p}=3.87$

$R$ supplier: $\mu_{Y}=0.4000 \quad \sigma_{Y}=0.4361 \stackrel{p}{D_{p}}=2.96$

If the performance of these three suppliers are drawn on the analysis chart of performance of formwork process, shown in figure 3 , it will indicate that $F$ supplier's performance is poor, $O$ supplier has the best performance and $R$ is fair. $O$ Supplier is the best choice. If the rate of as scheduled delivery is used, $O$ Supplier has the highest rate of 0.9998 . $R$ Supplier has a rate of 0.9969 and $F$ Supplier has the rate of 0.9876 . Hence, the index $D_{p}$ found by this paper can fully reflect the suppliers' performance of formwork process.

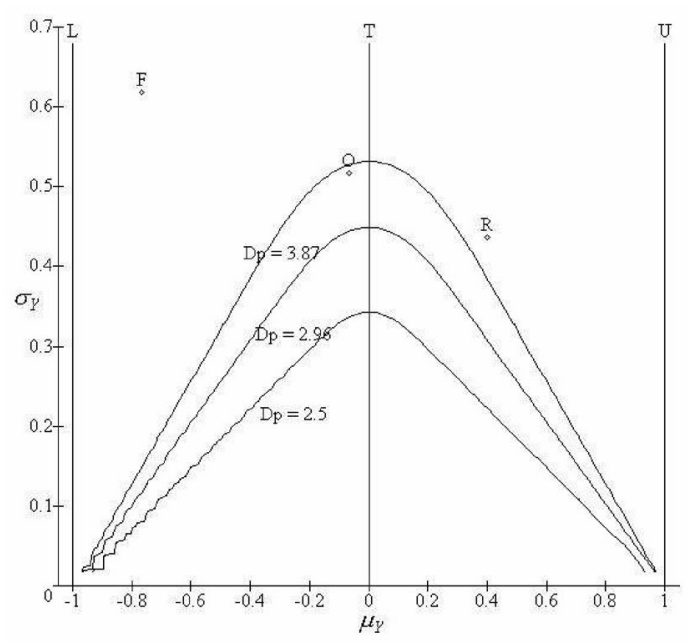

Fig. 3 The Analysis Chart of Performance of Formwork Process for F0, and R Formwork Supplier 


\section{Conclusion}

The index of performance of formwork process proposed by this paper is a convenient and effective tool in assessing the quality and delivery of multi-formworks. This research uses Taguchi's Loss Function as basis in developing the relationship between the index of performance of formwork process and the rate of as scheduled delivery. In addition, Vännman's (Vännman 1999) method is also used to plot the performance coordinate that is generated by the actual average value of performance of formwork process and the standard deviation on the analysis chart of performance of supplier. Suppliers and customers can judge the actual performance from the chart, which it serves as a basis for customers in selecting a decent supplier. In addition, the relationship between the index of performance of formwork process and $p$, the rate of as scheduled delivery can assist the suppliers an easy way to calculate the current condition of delivery. Thus, the suppliers can quickly recognize any problems and seek any possible improvements. But the assumption of this research is based on the normal distribution. The asymmetric theory will be considered in the future research to extend the applicability of this proposed method.

\section{References}

1) Gudmestad, O. T. and Warland, T. A. (1992) Optimum use of concrete structures for development of offshore fields, Proceedings of the International meeting on Petroleum Engineering, Mar. 2427.

2) Hanna, A. S, Willenbrock, J. H. and Sanvido, V. E. (1992) Knowledge acquisition and development for formwork selection system, Journal of Construction Engineering and management,
118(1), 179-198.

3) Dou, W. C., Zhang, F. Y., Li, D. B. and Zhang, S. Q. (2001) Study if enable technology in product data management, Computer Integrated Manufacturing Systems, 7(8), 49-53.

4) Ling, Y. Y. and Leo, K. C. (2000) Reusing timber formwork: Importance of workmen's efficiency and attitude. Building and Environment, 35(2), 135-143.

5) Render, S. (1995) Reinforcement prefabrication for fast-track construction. Concrete, 29(2), 10-12.

6) Dickson, G. W. (1966) An analysis of vendor selection systems and decisions. Journal of Purchasing, 2(1), 5-17.

7) Weber, C. A., Current, J.R. and Benton, W. C. (1991) Vendor selection criteria and methods. European Journal of Operational Research, 50, 2-18.

8) Kane, V. E. (1986) Process capability indices. Journal of Quality Technology, 18(1), 41-52.

9) Chan, L. K., Cheng, S. W. and Spiring, F. A. (1988) A new measure of process capability: $\mathrm{C}_{\mathrm{pm}}$. Journal of Quality Technology, 20(2), 162-175.

10) Boyles, R. A. (1991) The Taguchi capability index. Journal of Quality Technology, 23(1), 17-26.

11) Pearn, W. L., Kotz, S. and Johnson, K. L. (1992) Distribution and inferential properties of process capability indices. Journal of Quality Technology, 24(2), 216-231.

12) Boyles, R. A. (1994) Process capability with asymmetric tolerances. Journal of Tolerances, Communication in StatisticsSimulation and Computation, 23(3), 615-643.

13) Chen, K. S. (1998) Incapability index with asymmetric tolerances. Statistica Sinica, 8, 253-262.

14) Chen, K. S., Huang M. L. and Li, R. K., (2001) Process Capability Analysis for an Entire Product. International Journal of Production Research, 39(17), 4077-4087.

15) Chen, K. S., Chen, S. C. and Li, R. K., (2002) Process Capability Analysis of Capacitors. International Journal of Advance Manufacturing Technology, 19, 623-628.

16) Vänman, K. and Deleryd, M. (1999) Process capability plots - A quality improvement tool. Quality and Reliability International, $15,213-217$. 